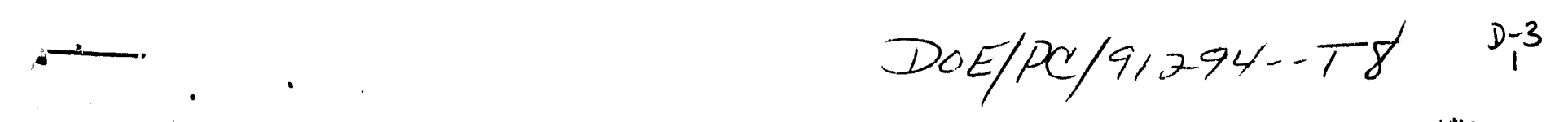

\title{
The Role of Pore Structure on Char Reactivity.
}

\section{DOE Grant No.: DE-FG 22-91PC91294 \\ Quarterly Progress Report}

\author{
P.I.: Adel F. Sarofim
}

Student: Angelo Kandas

\begin{abstract}
Massachusetts Institute of Technology Department of Chemical Engineering Cambridge, MA 02139-4307
\end{abstract}

Prepared for U.S. Department of Energy Morgantown Energy Technology Center P.O. Box 880 Morgantown, WW 26507-0880 Attention: Wu K. Lan

Date Submitted: October; 1993 
The Role of Pore Structure on Char Reactivity.

DOE Grant No.: DE-FG 22-91PC91294

Quarterly Progress Report

P.I.: Adel F. Sarofim

Student: Angelo Kandas

Massachusetts Institute of Technology

Department of Chemical Engineering

Cambridge, MA 02139-4307

Prepared for U.S. Department of Energy Morgantown Energy Technology Center P.O. Box 880

Morgantown, WW 26507-0880

Attention: Wu K. Lan

Date Submitted: October, 1993 


\section{Introduction}

The project is slowly shifting in its focus from development and refinement of the equipment and techniques to provide the data needed for pore modelling to one of actual data collection. Major work has been accomplished on getting the electrodynamic balance(EDE) to properly function and some exciting results have been obtained on the effect of pore opening on the reaction rate and the particle conductivity.

The continuing work on the EDB to be used in the measurement of single char particle reactivity has provided a system that is now functioning to the point were experiments are possible.

The control system to keep the particle in the center of the reaction chamber of the EDB has been modified to provide reasonable control of particles. Intense heat up rates still cause problems due to the inherent unevenness of heating from two sides causing the char particles to change lateral positions quicker than the current system can cope. However, this is not a problem when dealing with longer combustion times.

The laser cooling system of the EDB has also been improved to decrease power variation from $10 \%$ to $1 \%$. This will improve particle stability and remove the necessity for power control on the laser. The fine focusing of this new laser system continues. However, some work was done with the EDB before the laser system installation began.

The project has made progress on obtaining the particle diameters of particles suspended in the EDB. The system currently in use relies on a He-NE laser and electronic camera producing images shown in Figure 1. As can be seen, the image has a great deal of noise, even for the background subtracted data, due to diffraction in the optical system. By Plotting the intensity of the image versus radius, one can find the number of pixels corresponding to diameter, resulting in about a $10 \%$ error. This error is almost entirely due to the optical system, and not "real" diameter measurements using other methods. This is due to the simple system created to allow for extraction of the particles from the EDB for later measurement and characterization using techniques such as transition electron microscope work. This raises exciting possibilities about sectioning studies to determine porosities using microscopy for various burnouts.

The EDB has been used to determine the rates of reaction of Spherocarb particles. The results shown in Figure 2 indicate a long induction time before the reaction is initiated. This is a consequence of pore blocking with a large inaccessible area. To check this hypothesis the effective conductivity of the Spherocarb particles was determined as a function of burnout. This was achieved as part of a joint program with Dr. Bar-Ziv at Beu Gurion University. The conductivity could be inferred from the photophoretic force measured by turning the laser off periodically and correcting the measurement for natural convection. The effective conductivity of the solid decreased as the porosity at about the same time as the reaction rate accelerated. Figure 3 shows the results on the thermal conductivity as a function of burnout obtained both in out EDB and that at Ben Gurion. 
This provides an additional tool for looking at the evolution of pore structure.

Investigations of the pore structure of char is highly important to the study, and use of Small Angle X-Ray Scattering(SAXS) is being investigated. In contrast to nol mal X-Ray diffraction, SAX provides a way to measure the voids contained in a very small sample, such as our soots. An overview of the technique can be found in Levendis. The basic premise is that the pore diameters register as spacings in SAX, and by using integral techniques, once can obtain porosity distributions. Thus one can theoretically get a total surface area of the particles, and not just the accessible surface area. To see if differences were observable on the system at MIT, graphite and carbon black were tested(Figures 4 and 5), as they are essentially the limits of what we can expect in our soot work. Using these compounds, one can see that a great deal of difference exists between the two samples. However, we will not know if the limits of detectability are capable of differentiating partially combusted soots until actual soot samples are measured after combustion. The system will also be backed up by a full TEM workup of the soot samples.

The cages used in the Fluidized Bed work have proven to be successful in capturing the particles to be used in the study. The time delay in the study has been caused by delays in obtaining appropriate coal for our study. Currently, as West Virginia bituminous has been obtained, and a North Dakota Lignite has been ordered.

\section{Future Work}

The fluidized bed will be used to obtain chars at various sages of combustion in the Fluidized bed for a lignite and bituminous coal. Soots will be combusted to observe their porosity and structure using SAXS and TEM. The EDB system will be used to continue the study of the combustion of char particles.

\section{References:}

Levendis, Y.A., Flagan, R.C., "Synthesis, Formation and Characterization of Micron-Sized Glassy Carbon Spheres of Controlled Pore Structure," Carbon, 27, pp 265-283 1989.

\section{DISCLAIMER}




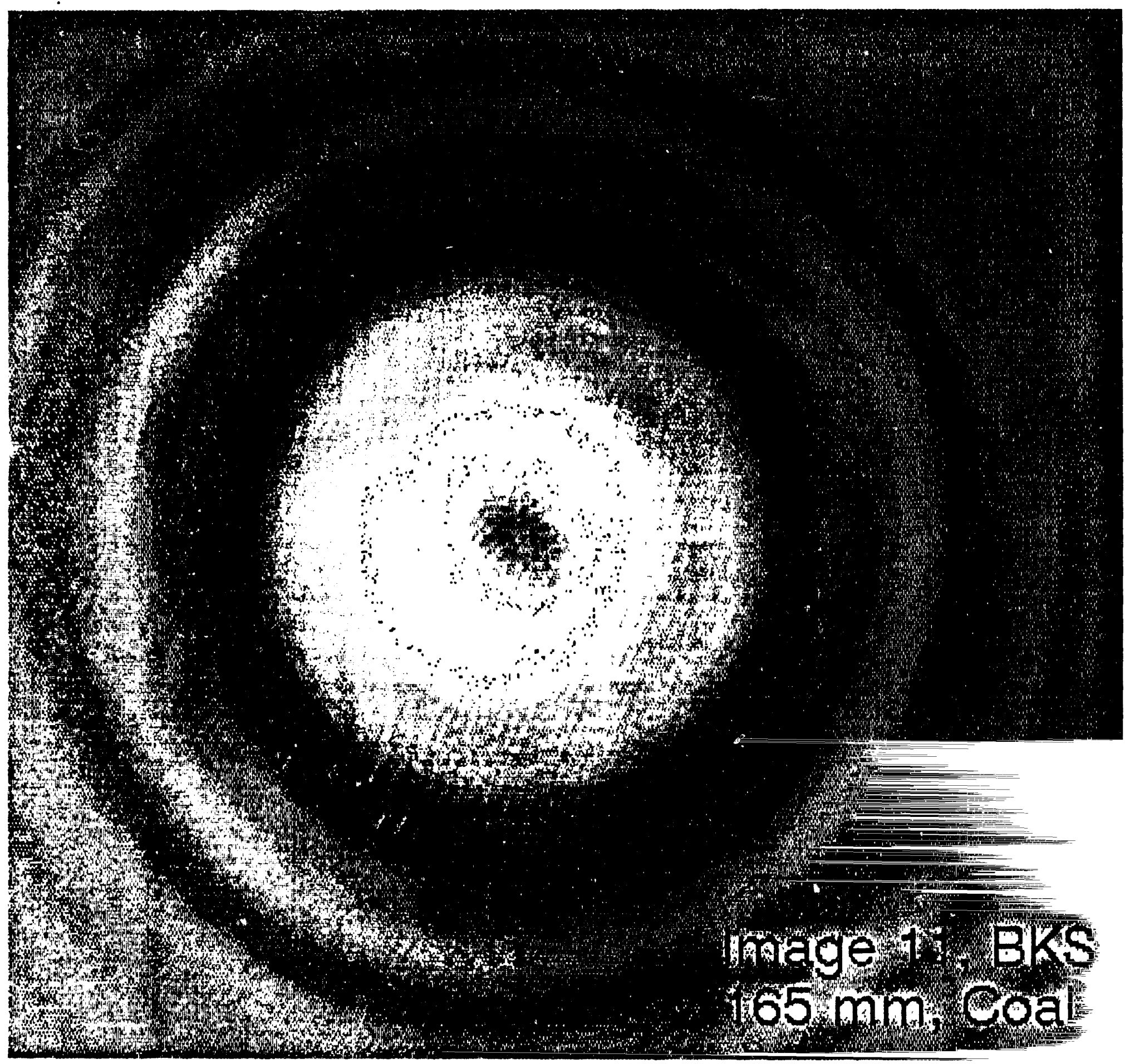

Figure 1. Image obtained from a Spherocarb particle. The particle diameter was measured to be $165 \mathrm{~mm}$ after removal. Also note that this is an inverted image on the print out, and the white area in the center is the particle image. 


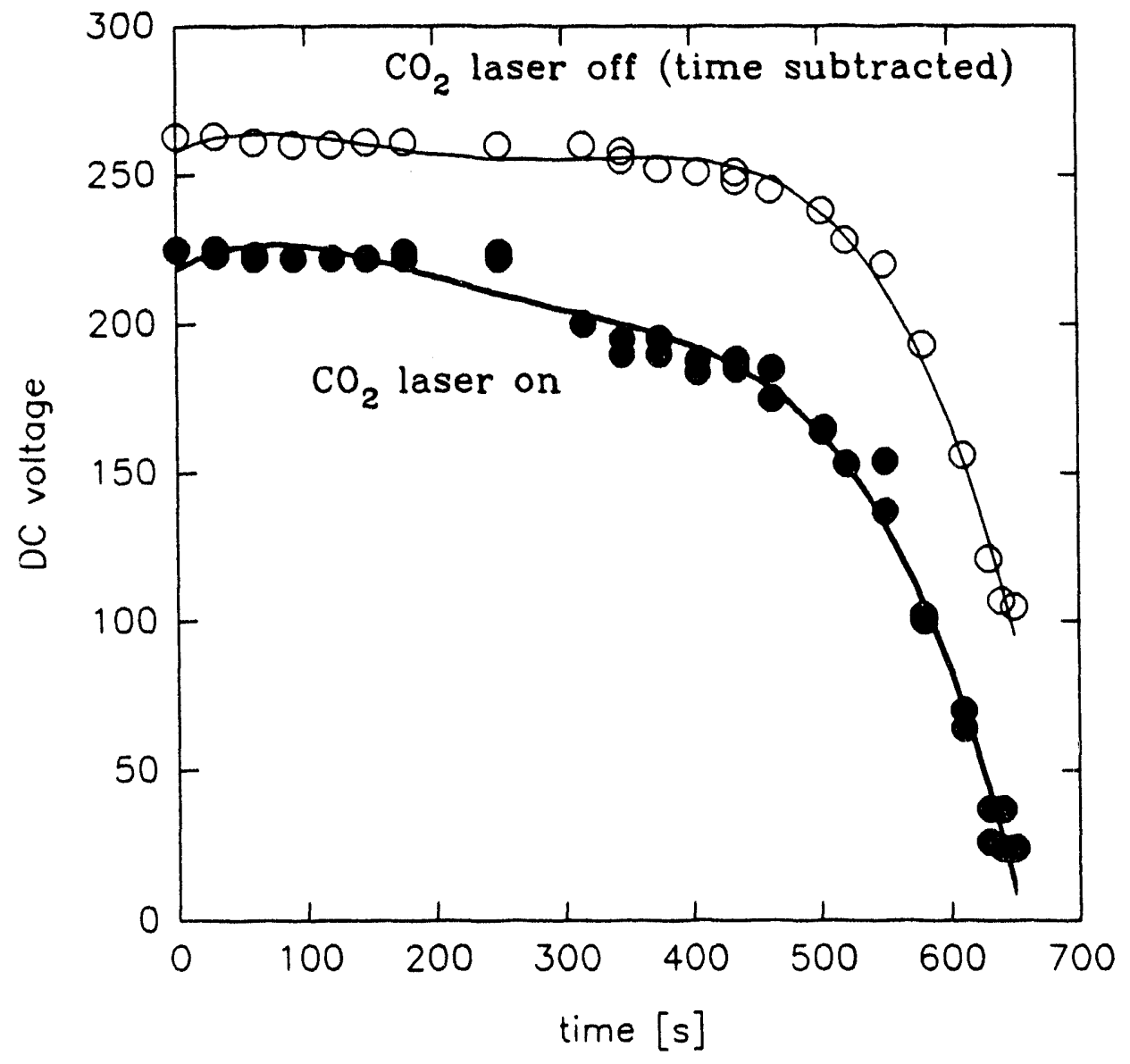

Figure 2. Combustion versus time for a char particle at $790 \mathrm{~K}$. Note the long induction time and that past 750 seconds, reaction rapidly takes place. The $\mathrm{CO}_{2}$ laser was turned on and off to allow for measurement of the photophoretic force. 


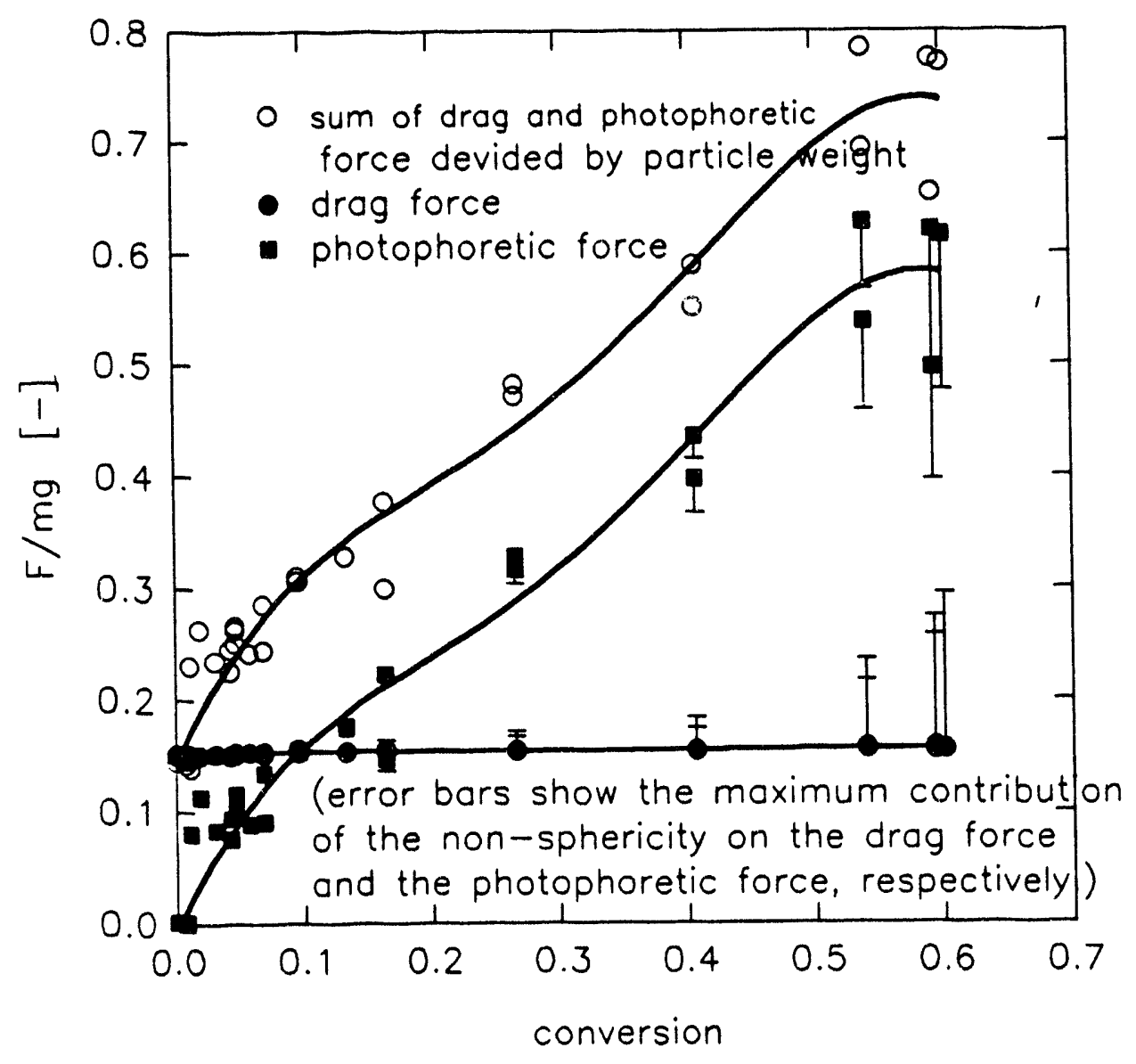

Figure 3. Forces affecting the weight(Voltage needed to maintain particle in center of the EDB). Since the diameter is relatively constant, only the photophoretic force can be particle. 


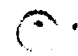

Figure 4. Example of SAXS taken on ungraphitized carbon black.

$-\mathrm{C}$

C

C

C

C

C

C

$C$

0

0

O

Q

$G$

C

6

c

$C$

0

G

(

$C$ 


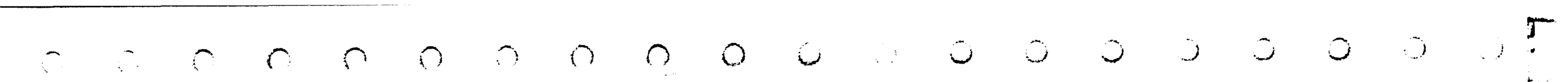

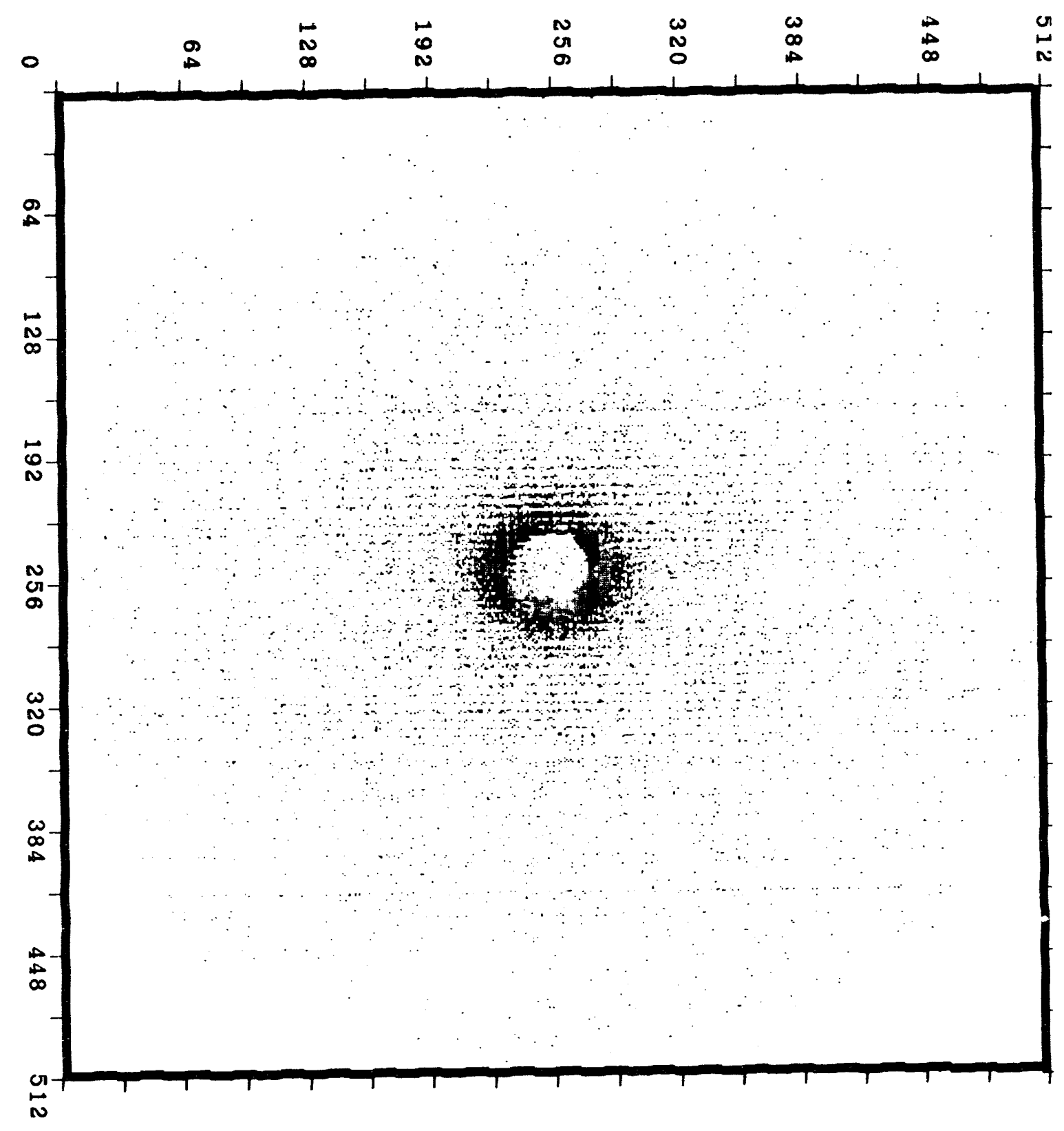

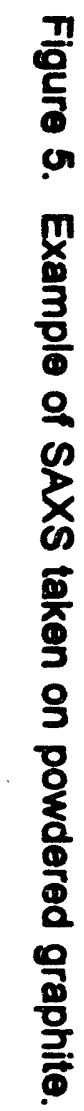


